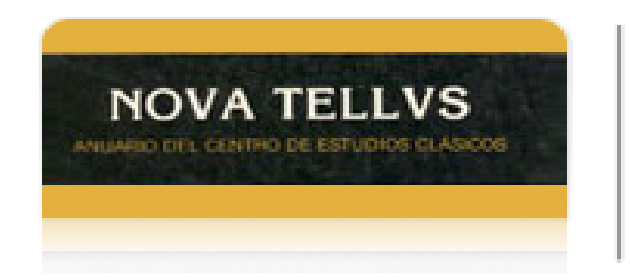

Nova Tellus

ISSN: 0185-3058

novatelu@servidor.unam.mx

Centro de Estudios Clásicos

México

Rinaldi, Daniel

Procedimientos intertextuales en Fedra y otras griegas de Ximena Escalante

Nova Tellus, vol. 26, núm. 2, 2008, pp. 293-321

Centro de Estudios Clásicos

Distrito Federal, México

Disponible en: http://www.redalyc.org/articulo.oa?id=59115497013

- Cómo citar el artículo

- Número completo

- Más información del artículo

Página de la revista en redalyc.org

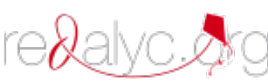

Sistema de Información Científica

Red de Revistas Científicas de América Latina, el Caribe, España y Portugal

Proyecto académico sin fines de lucro, desarrollado bajo la iniciativa de acceso abierto 


\title{
Procedimientos intertextuales \\ en Fedra y otras griegas de Ximena Escalante
}

\author{
Daniel RINALDI \\ Universidad Nacional Autónoma de México \\ drinaldip@hotmail.com
}

RESUMEN: En el presente artículo se aborda el estudio de la intertextualidad en la pieza Fedra y otras griegas de la mexicana Ximena Escalante. Se analizan con detenimiento los procedimientos intertextuales empleados por la dramaturga para reescribir el mito de Fedra e Hipólito. Se estudian tres ejemplos de transformación de textos previos; el primero, de Séneca; el segundo, de Racine; y el último, de sor Juana Inés de la Cruz.

$$
* * *
$$

ABSTRACT: In this article, we study intertextuality in Fedra y otras griegas, a play by the Mexican author, Ximena Escalante. We analyze the intertextual procedures the playwright employs in order to re-write the myth of Phaedra and Hippolytus. Three examples of transformation from prior texts are closely examined: the first from Seneca, the second from Racine and the last from sor Juana Inés de la Cruz.

PALABRAS ClAVE: Escalante, Fedra, Séneca, Racine, sor Juana, tradición clásica. RECEPCIÓN: 30 de mayo de 2008.

ACEPTACIÓN: 8 de agosto de 2008. 


\title{
Procedimientos intertextuales \\ en Fedra y otras griegas \\ de Ximena Escalante
}

\author{
Daniel RINALDI
}

Ximena Escalante (Ciudad de México, 1964), reescribe en Fedra y otras griegas, pieza teatral publicada en $1996^{1}$ y estrenada en $2002,{ }^{2}$ el mito de Fedra e Hipólito, ${ }^{3}$ mito que, en los últimos años, ha conocido importantes reescrituras; piénsese en Phaedra's Love (1996) de la dramaturga inglesa Sarah Kane (1971-1999), ${ }^{4}$ en Fedra (2007) del español Juan Mayorga $(1965)^{5}$ y en la ópera Phaedra (2007) de los alema-

\footnotetext{
${ }^{1}$ La obra fue publicada, en 1996, en la antología El nuevo teatro II y, en 2004, en un volumen independiente. En el presente artículo se la cita por esta última edición.

${ }^{2}$ Fedra y otras griegas se estrenó el 3 de junio de 2002 en el Teatro "El Granero" de la Ciudad de México bajo la dirección de José Caballero. El papel de Fedra lo representó Érika De La Llave; el de la Nana, Patricia Marrero; el de Ariadna, Arcelia Ramírez y el de Hipólito, Fabián Storniolo. La obra fue escrita con una beca del Fondo Nacional para la Cultura y las Artes (FONCA) del Consejo Nacional para la Cultura y las Artes (CONACULTA) del gobierno de México, bajo la tutoría del propio Caballero.

${ }^{3}$ Con frecuencia aborda Escalante los mitos literarios; piénsese en Yo también quiero un profeta (2003), reescritura del tema de Salomé y san Juan Bautista. La autora, perteneciente a una familia dedicada al teatro desde hace varias generaciones (su tatarabuelo dirigía el Teatro Custodio de Sevilla), es nieta del productor, director teatral y guionista de cine español, exiliado en México, Álvaro Custodio (1913-1992), autor, entre otras obras, de Eva y Don Juan (El mito de la seducción), reescritura del mito de Don Juan.

${ }^{4}$ Phaedra's Love fue estrenada en Londres, en el Gate Theatre, el 15 de mayo de 1996. La obra fue dirigida por la propia Sarah Kane.

${ }^{5}$ El estreno de Fedra tuvo lugar el 12 de julio de 2007 en la quincuagésimo tercera edición del Festival de Teatro Clásico de Mérida.
} 
nes Hans Werner Henze (1926), música, y Christian Lehnert (1969), libreto. ${ }^{6}$

Con respecto al origen de la pieza, señala la propia Escalante: "Fedra se gestó porque yo estaba leyendo esa obra y me gusta mucho la mitología".7 Esas lecturas así como su gusto por la mitología están presentes, de manera más o menos explícita, en su muy personal versión del tema. ${ }^{8}$ Subraya la autora:

Empecé a ver que alrededor de Fedra había muchas historias que no habían sido contadas: su infancia, su adolescencia y su muerte. Siempre habíamos visto una Fedra concentrada nada más en el amor de Hipólito, y me parecía tanto más interesante todos sus otros amores, toda su infancia, por ejemplo. Entonces me sumergí en la mitología y estudié mucho el mito de Fedra y a los personajes que intervienen en él. Es lo que te decía que me gusta, que alrededor de un personaje se conozcan todos los otros, y pues eso fue mi Fedra. Buscar fue muy divertido, me gustó mucho. Y así han sido todas las otras obras que he escrito, me meto en un personaje, en una historia y me sumerjo durante mucho tiempo en leer cosas. La escritura de la obra es muy rápida, cuando me

${ }^{6}$ La primera audición de Phaedra se realizó en el Staatsoper Unter den Linden de Berlín el 6 de septiembre de 2007.

${ }^{7}$ R. Benítez, "Ximena Escalante”, http://www.uv.mx/universo/129/arte/arte04. htm.

${ }^{8}$ Es por demás conocida la confusión terminológica que agobia a la tematología. Y si bien es cierto que, como observa P. Brunel, “Il n’y a pas de vérité absolue en matière de terminologie. Une terminologie n'est qu'un instrument nécessaire, commode et toujours révisable" ("Thématologie et littérature comparée", p. 3), no es menos cierto que esta confusión se ha vuelto un gran problema para los estudios tematológicos. Uno de los centros de la confusión, tal vez el más evidente, es el uso cruzado de los términos tema y motivo, "confusion babélienne" la ha llamado R. Trousson ("Les Études de thèmes. Questions de méthode", p. 2): lo que para la escuela alemana es motivo, para la anglosajona es tema, y viceversa; pero este señalamiento es demasiado simple como para resolver el problema. Ahora bien, dado que no se ha impuesto una terminología unitaria en el ámbito de estos estudios tematológicos, conviene señalar que, en la presente investigación, y de manera concisa, tema es el esquema narrativo, y motivo, un segmento, una pequeña unidad, un incidente elemental o un componente de dicho esquema. 
siento la puedo sacar en unos días, pero me gusta imaginarla mucho tiempo, pensarla y sentirla. ${ }^{9}$

A diferencia de la mayoría de las anteriores reescrituras literarias del mito, centradas casi exclusivamente en la pasión de la madrastra por el hijastro (piénsese en Eurípides, en Séneca o en Racine), Escalante incorpora, en la suya, otras "historias" consteladas alrededor de aquélla, entre ellas, la relación de Fedra con su hermana Ariadna, con su madre Pasífae y con su abuela Europa (lo que explica el y otras griegas del título de la obra), la relación de Ariadna con su hermano el Minotauro, la disputa de Teseo y Baco por Ariadna, ${ }^{10}$ "historias" que Escalante retoma, rehaciéndolas o transformándolas, de la tradición mítica grecolatina ${ }^{11}$ o que ella misma inventa.

Si bien el resultado es muy diferente, la gestación de la obra de Escalante no difiere de la de otras Fedras del siglo Xx: la lectura antecede siempre la escritura. ${ }^{12}$ El 3 de abril de 1909 escribe Gabriele D'Annunzio a su amigo Benigno Palmerio una carta en la que menciona los modelos de su tragedia: Eurípides - en el original griego, en una traducción latina y en la versión francesa de Leconte de Lisle-, Séneca, Racine, Swinburne, Plutarco y Ovidio. ${ }^{13}$ Y, en una entrevista que, por esos mismos días, concede el poeta a Renato Simoni, refiere:

La mia eroina è, come in Euripide, como nel Racine, tutta invasa dal morbo insanabile [...]. Ma non è le gemebonda inferma

\footnotetext{
${ }^{9}$ R. Benítez, "Ximena Escalante".

${ }^{10}$ Es importante destacar que Pasífae y Europa llegan a los sueños de Fedra, que el Minotauro llega a los sueños de Ariadna y que Baco llega a los de Teseo.

${ }^{11}$ Piénsese en la "variación", no exenta de humor, del abandono de Ariadna, por parte de Teseo, en la isla de Naxos. Escalante hace que Ariadna desembarque en un puerto (porque ya no quiere seguir el viaje), que Teseo se acerque a ella para despedirse, y que Ariadna vaya sola al bar de moda de la ciudad, el "Bar Naxos".

${ }^{12}$ Infelizmente no he podido encontrar declaraciones sustantivas de los autores contemporáneos arriba citados con respecto a la gestación de sus propias versiones.

${ }^{13}$ La entrevista apareció en Il Corriere della Sera el 9 de abril de 1909. G. D'Annunzio, Fedra, pp. XX-XXI.
} 
euripidea che giace sul suo tormentoso letto e non osa parlare a Ippolito né osa parlare a Tèseo, ma sol morire legando alle sue mani esangui le tavolette accusatrici. Né pur somiglia alla "grande dame" raciniana. ${ }^{14}$

El programa de escritura de la Fedra de Miguel de Unamuno puede seguirse también a través de la correspondencia privada del propio escritor. En una carta que dirige a Francisco Antón, fechada el 18 de abril de 1910, escribe:

Fuera de esto leo a los clásicos. Ahora a Eurípides. Y he concebido el propósito de hacer una Fedra moderna, de hoy. Voy a leer a Racine. Es un asunto inagotable. Sobre todo, la terrible némesis del amor que busca a quien no le busca a él. El que no le hace, el que no hace amor, le padece. Sería un drama terrible el de una mujer enamorada de un impotente o de un cura continente y casto. ${ }^{15}$

Y, el 6 de noviembre de 1911, escribe al actor Fernando Díaz de Mendoza:

he terminado otro tercer drama que se me figura le ha de convenir a usted más y sobre todo a su mujer, María Guerrero. Le creo más teatral, más rápido y más intenso. Se trata de Fedra, una Fedra moderna, cuya acción transcurre en nuestro tiempo. Del drama de Eurípides y del de Racine no tiene nada más que el argumento escueto, todo el desarrollo es distinto. ${ }^{16}$

Casi lo mismo escribe en una carta que envía al hispanista francés Jacques Chevalier el 3 de enero de 1912:

Este otoño he hecho una tragedia, Fedra, sobre el argumento mismo del Hipólito, de Eurípides, y la Phèdre, de Racine, pero

\footnotetext{
${ }^{14}$ G. D’Annunzio, Fedra, p. XII. La pieza fue estrenada el 10 de abril de 1909 en el "Teatro Lirico" de Milán por la compañía de Mario Fumagalli.

${ }^{15}$ M. de Unamuno, Teatro, p. 87.

${ }^{16}$ Ibidem, pp. 87-88.
} 
con un desarrollo completamente distinto y puesta la acción en la época contemporánea. La tragedia ocurre ahora y mi Fedra es cristiana. Creo haber hecho una obra de pasión. ${ }^{17}$

Héctor Mendoza, por su parte, confiesa las deudas de su $\mathrm{Fe}$ dra. Tragicomedia en dieciocho escenas para con otras Fedras. Escribe en este sentido el dramaturgo mexicano:

Reconocimiento de piraterías conscientes: Desde luego a Eurípides; pero también a Séneca, a Racine y a Plutarco. Muy abiertamente a Ovidio, en la traducción de Antonio Alatorre, y a Gabriele D’Annunzio, en la de Julio Gómez de la Serna. Un reconocimiento particular a la ayuda esclarecedora que me prestó el maravilloso libro de Robert Graves, The Greek Myths. ${ }^{18}$

Las "piraterías conscientes" son las influencias, más que reconocidas, elegidas por el propio autor, elección de influencias que, de manera evidente, orienta la reescritura del tema.

El comparatista alemán Manfred Beller, en el artículo "Thematologie" observa:

Vor allem aus Epos und Drama kennen wir klassische Mythen und historische Gestalten in bestimmten Situationen und unter überlieferten Namen als Stoffe. Die Eigenart der Charaktere, die Konstellation der Figuren und die Handlung ergeben sich aus den Motiven, beispielsweise dem Orakelmotiv (Ödipus) und dem Motiv der feindlichen Brüder (Eteokles und Polyneikes). Damit verbinden die Dichter die dem Stoff angemessenen, jeweils interesssierenden Themen. Im Falle der Antigone haben sie zeitwilig den Liebeskonflikt in die Figurenkonstellation Haimon-Antigone-Kreon [...], überwiegend aber den Gegensatz zwischen indi-

${ }^{17}$ Ibidem, pp. 89-90. La obra fue representada por primera vez el 25 de marzo de 1918 en el Ateneo de Madrid, en un acto organizado por la Sección de Literatura del mismo Ateneo.

${ }^{18}$ H. Mendoza, Secretos de Familia, p. 109. El estreno de la pieza tuvo lugar en 1988 en el Teatro "Juan Ruiz de Alarcón” de la Ciudad de México. 
vidueller moralischer Pflicht und Staatsräson in den Stoff hineingelegt. ${ }^{19}$

Señala, por una parte, que nunca Los siete contra Tebas de Esquilo, la Antígona de Sófocles y Las fenicias de Eurípides impidieron a un dramaturgo escribir su propia versión de los conflictos de la casa real de Tebas, y por otra que, sin la lectura de los clásicos griegos, Jean Racine no hubiera escrito $L a$ Thébaÿde ou les frères ennemis (1664), Jean Anouilh su Antigone (1944), ni Rolf Hochhuth (1966) y Leopold Ahlsen (1968) su Berliner Antigone. ${ }^{20}$

Fedra y otras griegas es también una escritura de múltiples lecturas. En la obra es imposible separar la escritura de la lectura porque, como se sabe, siempre se escribe lo ya escrito, lo ya leído, o, en palabras de Julien Gracq, "Déjà dit, ainsi ou autrement, et à redire encore". ${ }^{21}$ Volver a decir lo dicho o reescribir lo escrito, lo leído, no es, como también se sabe, imitarlo - de forma servil o no-; es volver a crearlo; es, etimológicamente, re-crearlo. En este sentido, conviene recordar la afirmación de Jorge Luis Borges: "todo escritor escribe algo que ya existía". ${ }^{22}$ Y conviene también no olvidar que sin recursividad (palabra que escamotea el Diccionario de la Academia) no hay tema. Escalante recurre a otros textos $\mathrm{y}$, de muy diferentes maneras, los recrea en el suyo. Ahora

${ }^{19}$ M. Beller, "Thematologie" p. 75: "Es sobre todo a partir de la poesía épica y del drama que conocemos como argumentos [Stoffe] mitos clásicos y figuras históricas en situaciones determinadas y bajo nombres tradicionales. La peculiaridad de los caracteres, la constelación de las figuras y la acción resultan de los motivos [Motiven], por ejemplo el motivo del oráculo (Edipo) y el motivo de los hermanos enemigos (Eteocles y Polinices). Con ello relacionan los poetas los temas [Themen] que se adecuan al argumento [Stoff], y que respectivamente les interesan. En el caso de la Antígona, han tratado en el argumento [Stoff] el conflicto del amor en la constelación de las figuras Hemón-Antígona-Creonte [...], pero preponderantemente la contraposición entre deber moral individual y razón de Estado".

${ }^{20}$ M. Beller, "Thematologie", p. 75.

${ }^{21}$ J. Gracq, En lisant en écrivant, p. 121.

${ }^{22}$ L. Block de Behar, Una retórica del silencio..., p. 79. 
bien, como observa David Olguín, director de Ediciones El Milagro, "No estamos ante un cóctel de fuentes eruditas o una reescritura escolástica. Para esta dramaturga el oficio no basta". ${ }^{23}$ Escalante, en efecto, hace dialogar creativamente su texto con esos otros textos, esto es, establece con ellos un variado y erudito "diálogo" intertextual.

El estudio de la intertextualidad (intertextualité) desarrolla-

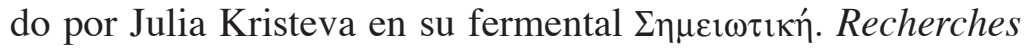
pour une sémanalyse, libro publicado en 1969, tiene sus antecedentes, como es bien sabido, en los trabajos de Mikhail Bakhtine sobre el enunciado dialógico o polifónico. ${ }^{24}$ En uno de los ensayos señala la autora que:

dans l'univers discursif du livre, le destinataire est inclus uniquement en tant que discours lui-même. Il fusionne donc avec cet autre discours (cet autre livre) par rapport auquel l'écrivain écrit son propre texte; de sorte que l'axe horizontal (sujet-destinataire) et l'axe vertical (texte-contexte) coïncident pour dévoiler un fait majeur: le mot (le texte) est un croisement de mots (de textes) où l'ont lit au moins un autre mot (texte).

\section{Y agrega:}

tout texte se construit comme mosaïque de citations, tout texte est absorption et transformation d'un autre texte. À la place de la notion d'intersubjectivité s'installe celle d'intertextualité, et le langage poétique se lit, au moins, comme double..$^{25}$

En cuanto al lenguaje poético, ${ }^{26}$ un tipo de funcionamiento semiótico entre las numerosas prácticas significantes, observa:

\footnotetext{
${ }^{23}$ Sin firma, "Fedra y otras griegas revienta historias", p. 46.

${ }^{24}$ El libro recoge, con el título "Le mot, le dialogue et le roman", el fundamental artículo "Bakhtine, le mot, le dialogue et le roman", anteriormente aparecido en la revista Critique (XXIII, 239, Paris, avril 1967, pp. 438-465).

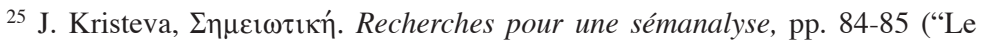
mot, le dialogue et le roman").

${ }^{26}$ Se refiere a la función poética del lenguaje de Roman Jakobson.
} 
Le signifié poétique renvoie à des signifiés discursifs autres, de sorte que dans l'énoncé poétique plusieurs autres discours sont lisibles. Il se crée, ainsi, autour du signifié poétique, un espace textuel multiple dont les éléments sont susceptibles d'être appliqués dans le texte poétique concret. Nous appellerons cet espace intertextuel. Pris dans l'intertextualité, l'énoncé poétique est un sous-ensemble d'un ensemble plus grand qui est l'espace des textes appliqués dans notre ensemble. ${ }^{27}$

Esto es, el sentido de un texto, independientemente de su contenido semántico, está condicionado por los textos anteriores. Para la cabal comprensión de un texto es necesario el conocimiento de otros textos previos a los que reenvía y con los que dialoga.

Gérard Genette publica, en 1982, Palimpsestes. La littérature au second degré, libro en el que expone su teoría de la transtextualidad (transtextulité) o trascendencia textual del texto (transcendance textuelle du texte). Distingue el crítico cinco diferentes formas de presencia de un texto en otro: la intertextualidad (intertextualité), la paratextualidad (paratextualité), la metatextualidad (métatextualité), la hipertextualidad (hypertextualité) y la architextualidad (architextualité).

La intertextualidad es la "relation de coprésence entre deux ou plusieurs textes, [...] la présence effective d'un texte dans un autre", ${ }^{28}$ relación que toma la forma de la cita (citation), el plagio (plagiat) y de la alusión (allusion). Explica:

Sous sa forme la plus explicite et la plus littérale, c'est la pratique traditionnelle de la citation (avec guillemets, avec ou sans référence précise); sous une forme moins explicite et moins canonique, celle du plagiat (chez Lautréamont, par exemple), qui est un emprunt non déclaré, mais encore littéral; sous forme encore moins explicite et moins littérale, celle de l'allusion, c'est-à-dire

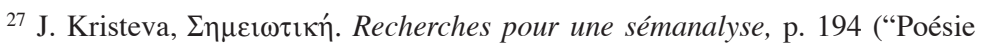
et négativité").

${ }^{28}$ G. Genette, Palimpsestes..., p. 8.
} 
d'un énoncé dont la pleine intelligence suppose la perception d'un rapport entre lui et un autre auquel renvoie nécessairement telle ou telle de ses inflexions, autrement non recevable. ${ }^{29}$

La paratextualidad es una relación

généralement moins explicite et plus distante, que [...] le texte proprement dit entretient avec ce que l'on ne peut guère nommer que son paratexte: titre, sous-titre, intertitres; préfaces, postfaces, avertissements avant-propos, etc.; notes marginales, infrapaginales, terminales; épigraphes; illustrations; prière d'insérer, bande, jaquette, et bien d'autres types de signaux accessoires, autographes ou allographes, qui procurent au texte un entourage (variable) et parfois un commentaire officiel ou officieux, dont le lecteur le plus puriste et le moins porté à l'érudition ne peux pas toujours disposer aussi facilement qu'il le voudrait et le prétend. ${ }^{30}$

La metatextualidad es la relación, de "comentario" (commentaire), "qui unit un texte à un autre texte dont il parle, sans nécessairement le citer (le convoquer), voire, à la limite, sans le nommer"; ${ }^{31}$ es, por excelencia, la relación crítica (critique). La hipertextualidad es "toute relation unissant un texte $\mathrm{B}$ (que j'appellerai hypertexte) à un texte antérieur A (que j'appellerai, bien sûr, hypotexte) sur lequel il se greffe d'une manière qui n'est pas celle du commentaire", ${ }^{32}$ vale decir, un hipotexto es "tout texte dérivé d'un texte antérieur par transformation simple (nous dirons désormais transformation tout court) ou par transformation indirecte: nous dirons imitation "; 33 estas operaciones transformativas también son llamadas por el autor transformación directa (directe), la simple, y comple-

\footnotetext{
${ }^{29}$ Ibid., p. 8.

${ }^{30}$ Ibid., p. 9.

${ }^{31}$ Ibid., p. 10.

${ }^{32}$ Ibid., pp. 11-12.

${ }^{33}$ Ibid., p. 14.
} 
ja (complexe), la indirecta. La architextualidad es la relación más abstracta y la más implícita, "de pure appartenance taxonomique". ${ }^{34}$

En su reescritura del tema de Fedra e Hipólito, Escalante recurre a distintas formas de transtextualidad, según las categorías de Genette. En cuanto a la hipertextualidad, Fedra $y$ otras griegas es un hipotexto, un texto derivado por transformación de diversos textos anteriores. Sus hipertextos son, entre otros, las tragedias Hipólito portador de corona (428 a. C.) de Eurípides, Fedra (entre 48 y 65) de Séneca y Phèdre (1677) de Jean Racine, así como la comedia Amor es más laberinto (1689) de Sor Juana Inés de la Cruz y de fray Juan de Guevara.

De los muchos ejemplos de intertextualidad, siempre según las categorías de Genette, se destacan dos; uno dialoga con Séneca y el otro con Racine. En la primera escena de la tercera parte, dice la Nana a Fedra:

Vas al precipicio a sabiendas. Detén tu locura y ayúdate a ti misma: parte de la curación es querer ser curado. ${ }^{35}$

En esta brevísima intervención combina Escalante tres versos de la tragedia latina. Al comienzo de obra, la nodriza (nutrix) ruega a la reina que domine su pasión; ésta responde:

[...] Quae nemoras scio

vera esse, nutrix; sed furor cogit sequi

peiora. Vadit animus in praeceps sciens

remeatque frustra sana consilia appetens.

[...] Sé, nodriza, que es verdad

lo que recuerdas, pero mi pasión me fuerza

\footnotetext{
${ }^{34}$ Ibid., p. 11.

${ }^{35}$ X. Escalante, Fedra y otras griegas, p. 80.
} 
a seguir lo peor. A sabiendas va mi alma al precipicio

y regresa, pero en vano, deseosa de buenos consejos.

$$
\text { (vv. 177-180) })^{36}
$$

Más adelante la nodriza vuelve a rogar a Phaedra que detenga su furor, su locura, su loca pasión erótica:

Per has senectae splendidas supplex comas

fessumque curis pectus et cara ubera

precor, furorem siste teque ipsa adiuna:

pars sanitatis velle sanari fuit.

Por esta resplandeciente cabellera de la vejez, por este pecho cansado de preocupaciones y por estos senos que te son queridos, suplicante, te ruego:

detén tu locura y ayúdate a ti misma; parte de la sanación es querer ser sanado.

(vv. 246-249)

La dramaturga leyó, como lo muestran las mismas palabras, la traducción española de Jesús Luque Moreno, catedrático de Filología Latina de la Universidad de Granada, traducción publicada en la Biblioteca Clásica Gredos:

Lo que me estás recordando sé que es verdad, nodriza, pero mi loca pasión me fuerza a seguir el peor camino. Va mi alma al precipicio a sabiendas e intenta volver atrás ambicionando en vano unos sanos propósitos. ${ }^{37}$

Y

Por esta cabellera en la que resplandece la vejez y este pecho cansado de preocupaciones y estos senos que te son queridos, suplicante, te lo ruego: detén tu locura y ayúdate a ti misma: parte de la curación es querer ser curado. ${ }^{38}$

\footnotetext{
${ }^{36}$ Tanto en estos versos, como en los siguientes, las bastardillas son mías.

${ }^{37}$ Séneca, Tragedias II..., p. 35.

${ }^{38}$ Ibid., p. 38.
} 
En la intervención de la Nana, Escalante cita, reutilizándolas, una intervención de Phaedra y otra de la nutrix. Tanto Séneca como la dramaturga mexicana dan a "praeceps" / "precipicio" el mismo sentido figurado de "ruina moral" (sentido figurado que es casi un lugar común) y subrayan que Phaedra / Fedra se precipita "sciens" / "a sabiendas", esto es, con conocimiento y deliberación, si bien lo hacen desde perspectivas distintas. En la tragedia latina, íntimamente sabe la reina que, deseando a Hippolytus, se dirige al precipicio y así lo expresa. En la pieza contemporánea Fedra también lo sabe, pero es su Nana quien le señala que, al desear a su hijastro, se encamina a la perdición. ${ }^{39}$

En la Phèdre de Racine, la reina cuenta a Enone, su suivante, el origen de su amor por Hippolyte. Apenas unida a Thésée, conoció, en Atenas, a aquél:

Je le vis, je rougis, je pâlis à sa vue;

Un trouble s'éleva dans mon âme éperdue;

Mes yeux ne voyaient plus, je ne pouvais parler;

Je sentis tout mon corps et transir et brûler.

(Acto primero, escena tercera, vv. 273-276)

En la obra de Escalante, Fedra espía a Hipólito por el ojo de la cerradura. Éste, inesperadamente, abre la puerta de su cuarto:

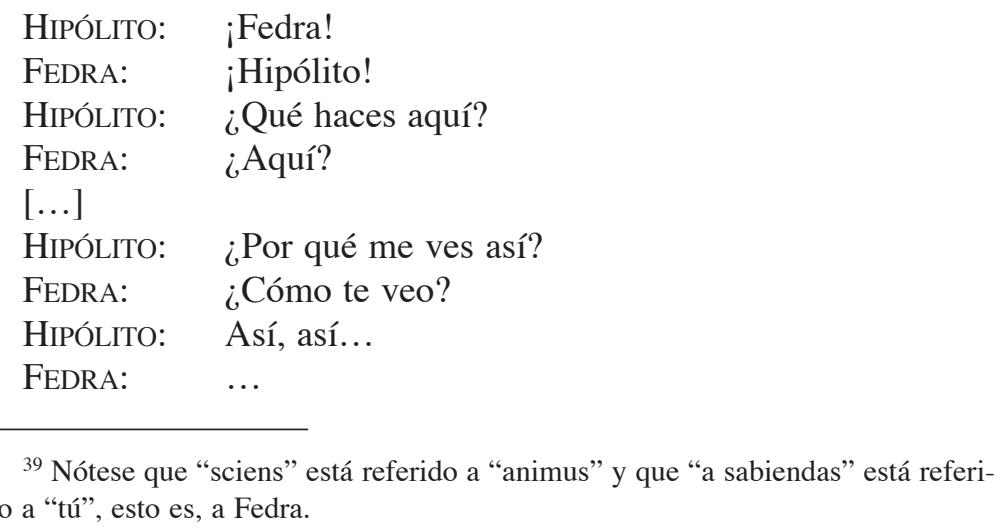




\begin{tabular}{|c|c|}
\hline HIPÓLITO: & ¿Qué te pasa? \\
\hline FEDRA: & ¿De qué? \\
\hline HiPÓLITO: & Estás... \\
\hline FEDRA: & ¿Cómo? \\
\hline HIPÓLITO: & No sé... estás... \\
\hline FEDRA: & ¿Cómo? \\
\hline HiPÓLITO: & ... ¿qué me ves? \\
\hline FEDRA: & $\ldots$ \\
\hline HiPÓlito: & ¿Por qué me ves así? \\
\hline FEDRA: & $\ldots$ \\
\hline HiPÓlito: & Tiemblas. \\
\hline FEDRA: & $\ldots$ \\
\hline HiPÓlito: & Estás pálida. \\
\hline FEDRA: & $\ldots$ \\
\hline HIPÓLITO: & Sin color. \\
\hline FEDRA: & $\ldots$ \\
\hline HiPÓLITO: & Caliente. \\
\hline FEDRA: & $\ldots$ \\
\hline HiPÓLITO: & Sudas. \\
\hline FEDRA: & $\ldots$ \\
\hline HIPÓLITO: & ¿Qué te pasa? \\
\hline
\end{tabular}

(Tercera parte, escena sexta) ${ }^{40}$

Este rápido diálogo reenvía a los cuatro versos de Racine. Tras haber realizado una transformación compleja de los mismos, la dramaturga mexicana los alude. Sólo conociéndolos, es evidente, se comprende la alusión. Las correspondencias léxicas son claras: "Je le vis" / “¿qué me ves?”, "je pâlis à sa vue" / "Estás pálida", "Je sentis tout mon corps et transir et brûler" / "Caliente". Los repetidos silencios de Fedra (“...") corresponden a: "je ne pouvais parler", y el ver sin ver, esto es, el ver en el vacío (que, evidentemente, sólo se actualiza en la representación de la pieza): ¿Por qué me ves así?”, a: “Mes

${ }^{40}$ X. Escalante, Fedra y otras griegas, pp. 90-91. 
yeux ne voyaient plus". Escalante transforma radicalmente el pasaje raciniano: vuelve acción la narración de los hechos. Ahora bien, lo que en Racine, Phèdre dice de sí misma, en Escalante, Hipólito lo dice de Fedra y se lo dice. En la obra francesa Phèdre enumera los efectos físicos de la pasión; en la mexicana, en cambio, estos mismos efectos son enumerados por Hipólito. Phèdre cuenta lo que experimenta; Hipólito refiere lo que el rostro de Fedra no puede ocultar.

Particularmente interesante para el estudio de las relaciones intertextuales es el centón de la escena sexta de la primera parte de la obra. Un "centón" es, como se sabe, una obra literaria, en verso o en prosa, compuesta, enteramente o en su mayor parte, de fragmentos ajenos, tomados de un único o de diferentes autores, que se hacen pasar o no como propios. El nombre deriva del latín cento, término con el que se designaba, en el mundo romano, un paño acolchado hecho de pedazos cosidos de distintas telas (paño que, embebido en agua o en vinagre, servía para apagar fuegos o pequeños incendios y que se empleaba también como protección contra las llamas) o una vestimenta (una especie de capa) hecha de retazos de tejidos y con el que, por extensión, pasaron a designarse, ya en la Antigüedad, este tipo de composiciones. ${ }^{41}$ El más antiguo centón latino conservado es la Medea atribuida a Hosidio Geta ( ¿siglo II d. C.?), ${ }^{42}$ tragedia compuesta en su totalidad con versos de Virgilio; y el más conocido, el Cento Nuptialis de Décimo

${ }^{41}$ Véanse: A. Walde, Lateinisches etymologisches Wörterbuch, s. v. "centō"; A. Ernout et A. Meillet, Dictionnaire étymologique de la langue latine. Histoire des mots, s. v. "centō"; H. Frisk, Griechisches etymologisches Wörterbuch, s.

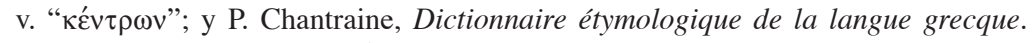

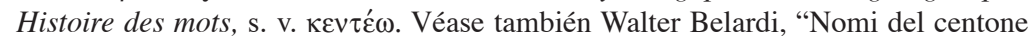
nelle lingue indoeuropee", en Ricerche linguistiche 4, 1958, pp. 29-57.

${ }^{42}$ Escribe Tertuliano en De praescriptione haereticorum: "Vides hodie ex Vergilio fabulam in totum aliam componi materia secundum versus, versibus secundum materiam concinnatis. Denique Hosidius Geta Medeam tragoediam ex Vergilio plenissime exsuxit" (c. 39), citado por N. Dane II, "The Medea of Hosidius Geta", p. 75 . 
Magno Ausonio (hacia 310-395), igualmente armado con versos de Virgilio. ${ }^{43}$ El mismo Ausonio, en la carta introductoria que dirige al maestro de retórica Axio Paulo, escribe:

Centonem vocant, qui primi hae concinnatione luserunt. sola memoria negotium sparsa colligere et integrare lacerata, quod ridere magis quam laudare possis.

Lo llamaron centón los primeros que se divirtieron con esta clase de ajustes. El trabajo es únicamente cuestión de memoria: recoger fragmentos sueltos e integrar los trozos inconexos [en un nuevo todo], de lo que puedes reírte más que elogiar.

Y agrega:

accipe igitur opusculum de inconexis continuum, de diversis unum, de seriis ludicrium, de alieno nostrum.

Acepta, pues, esta pequeña obra: un todo continuo hecho de elementos inconexos; una unidad hecha de partes diversas; una chanza hecha de cosas serias; mío aunque hecho de material ajeno.

Para armar su centón, Escalante toma versos de Amor es más laberinto, obra, como ya se ha señalado, de sor Juana Inés de la Cruz y de fray Juan de Guevara, en la que Ariadna y Fedra, las hijas del rey Minos, se disputan el amor de Teseo quien, enamorado de Fedra, con el consentimiento de ésta finge estarlo de Ariadna, porque ella posee la clave que lo habrá de sacar del laberinto. La monja jerónima es autora tanto de la loa que precede a la comedia ${ }^{44}$ como de los jornadas primera

${ }^{43}$ Véase Scott McGill, Virgil Recomposed: The Mythological and Secular Centos in Antiquity. New York: American Philological Association, 2005 (American Classical Studies, 48).

${ }^{44}$ Amor es más laberinto es, según Karl Vossler, una "comedia mitológica, galante, antiguo-barroca" ("Die mythologische, galante, antik-barrocke Komödie Amor 
y tercera; y el capellán del convento de Santa Inés, de la jornada segunda. La obra fue estrenada el martes 11 de enero de 1689 en el Palacio Virreinal de la Ciudad de México, ${ }^{45}$ como regalo para el trigésimo virrey de la Nueva España, don Gaspar Melchor Baltasar de Sandoval Cerda Silva y Mendoza, señor de Sazedón y Tortola, octavo conde de Galve, del hábito de Alcántara, ${ }^{46}$ en ocasión de su primer cumpleaños en tierras americanas. La comedia, cuyo título proviene del último verso de la jornada segunda, ilustra la idea del amor como un laberinto. ${ }^{47}$ Amor es más laberinto muestra, en efecto, que el sentimiento amoroso es más enredado y confuso ("laberíntico") que el propio edificio construido por Dédalo.

es más laberinto", Die "zehnte Muse von Mexico" Sor Juana Inés de la Cruz, p. 15), según Alfonso Méndez Plancarte, una "chispeante" "comedia” "mitológicogalante" ("Introducción”, en Juana Inés de la Cruz, Lírica personal, p. XXXIII), definición que, sin decirlo, el sacerdote toma de K. Vossler; según Alberto G. Salceda, una "comedia de capa y espada" ("Introducción", en Juana Inés de la Cruz, Comedias, sainetes y prosa, p. XXIII); según Octavio Paz, "una comedia de intriga galante, equívocos y duelos" (Sor Juana Inés de la Cruz..., p. 401); y según Guillermo Schmidhuber de la Mora, una comedia de "falda y empeño" (Sor Juana dramaturga, sus comedias "de falda y empeño", p. 7).

${ }^{45}$ Alberto G. Salceda, "Introducción”, en Juana Inés de la Cruz, Comedias, sainetes y prosa, p. XXI. Amor es más laberinto aparece recogido en el segundo volumen de las obras de sor Juana Inés de la Cruz, volumen impreso en Sevilla, en 1692, por Tomás López de Haro.

${ }^{46}$ El orden de los apellidos varía en los diferentes textos: de Silva Sandoval y Mendoza, de Sandoval Silva y Mendoza, de la Cerda y Sandoval, de la Cerda Sandoval Silva y Mendoza, de Silva y Sandoval, etc. El conde de Galve (16351697), era el segundo hijo de don Rodrigo Díaz de Vivar de Silva y Mendoza (1614-1676), cuarto duque de Pastrana, y de doña Catalina Gómez de Mendoza y Sandoval (o Gómez de Sandoval y Mendoza) (1616-1686), octava duquesa de Infantado, y estaba casado en segundas nupcias con doña Elvira María de Toledo (muerta en 1700), hija del séptimo marqués de Villafranca del Bierzo, con la que no tuvo hijos. El conde de Galve fue nombrado virrey por Carlos II; llegó a la Ciudad de México el 18 de noviembre de 1688 y tomó posesión del virreinato el día 20 de dicho mes; gobernó hasta el 27 de febrero de 1696.

${ }^{47}$ No hay que olvidar que el laberinto es una imagen clave de la estética barroca. 
En la escena sexta de la primera parte de la obra de Escalante intervienen Teseo y Ariadna que, según la acotación, están "lejos, detrás de unos árboles": ${ }^{48}$

TESEO: Dulce imán de mis sentidos,

Deja que a tus plantas ponga mis labios.

ARIADNA: Alza del suelo,

Que no es razón, cuando gozas

Todo el dominio del alma,

Que así estés.

TeSeO: $\quad$ Ariadna, os lleváis la pala

De ser mi dulce homicida;

Pues ha de quitar la vida

Por fuerza, quien roba el alma.

ARIADNA: Teseo mío, dispón

De mi vida y mi persona,

Que a quien dice que te quiere,

Todo lo demás le sobra.

TESEO: Mucho temo que reviente

El volcán en que me abraso.

Ariadna: Mucho temo que se asome

Esta pasión a los labios.

Se besan

Teseo: $\quad$ Yo soy

El que soy porque soy vuestro,

Porque mi ser, de mi amor

Depende, y a no ser vuestro,

pienso que no fuera yo.

ARIADNA: ¿Qué es lo que a mí me sucede...?

TESEO: Determinado me alisto...

Para morir...

Para padecer...

Tu amante.

Ariadna: ... siento que en mis confusiones, Amor es más laberinto.

${ }^{48}$ X. Escalante, Fedra y otras griegas, p. 21. 
TESEO: $\quad$ Noche oscura

Ampara mi amor, pues siempre

Empeños de amor ayudas. ${ }^{49}$

En otra acotación, texto secundario dirigido al director y a los actores, señala la autora: "Se besan, se pierden entre los árboles, en la noche". 50

Escalante elige (legit: "recoge" / "lee", y eligit: "escoge") y selecciona (seligit: "escoge y pone aparte") ${ }^{51}$ versos de la obra novohispana. Ya desmontados, vuelve a montarlos en su obra, y en este montaje, en esta nueva disposición, adquieren un sentido completamente nuevo. A la elección y selección de versos, sigue una reubicación que se traduce en resignificación.

Los seis primeros versos reproducen, sin cambio, un fragmento de un diálogo de Amor es más laberinto, pero lo que sor Juana hace decir a Fedra, Escalante se lo hace decir a Ariadna.

TESEO: Dulce imán de mis sentidos, Deja que a tus plantas ponga mis labios.

ARIADNA: Alza del suelo,

Que no es razón, cuando gozas

Todo el dominio del alma,

Que así estés.

Teseo: Dulce imán de mis sentidos,

deja que a tus plantas ponga

mis labios.

FEDRA: Alza del suelo, que no es razón, cuando gozas

\footnotetext{
${ }^{49}$ Ibid., pp. 21-22.

${ }^{50}$ Ibid., p. 22.

${ }^{51}$ Con insistencia observa Lisa Block de Behar: "no está de más recuperar una etimología bastante atenuada y reconocer que todo lector es un e-lector, en tanto que lee, que elige, más todavía, es un se-lector porque elige por sí mismo y para sî’, Una retórica del silencio..., p. 63.
} 
todo el dominio del alma, que así estés.

(Jornada tercera, escena IX, vv. 635-640)

A continuación, y con ligeras modificaciones, ${ }^{52}$ Escalante pone en boca de Teseo unos versos dichos, en la comedia novohispana, también por él pero dirigidos a Fedra. Ésta le señala al príncipe de Atenas que siempre se puede encontrar un remedio para las penas. ${ }^{53} \mathrm{Al}$ paño, Ariadna, que infiere que su hermana quiere liberarlo, se dispone a hacerlo ella misma.

TeSeO: $\quad$ Ariadna, os lleváis la pala

De ser mi dulce homicida;

Pues ha de quitar la vida

Por fuerza, quien roba el alma.

TeSEO: ¿Con qué pagaré el cuidado de favor tan desmedido, sí aun queda lo agradecido, por lo corto, desairado?

¡Oh! ¡Quién con vida se hallara y a vuestros pies la pusiera, que yo por vos me muriera aunque nadie me matara!

Mas siempre os lleváis la palma de ser mi dulce homicida; pues ha de quitar la vida por fuerza, quien roba el alma.

(Jornada primera, escena V, vv. 864-867)

La sustitución de "palma" por "pala" produce un sentido nuevo en la frase. ${ }^{54}$ La locución verbal "llevarse alguien la palma"

${ }^{52}$ Las modificaciones aparecen marcadas en bastardilla.

${ }^{53}$ Vv. 849-852: "Y así, pensad que habrá medio / de remediar pena tanta, / que entre el hierro y la garganta, / puede caber el remedio".

${ }^{54}$ Recuérdese el ejemplo que da G. Genette: el proverbio "Le temps est un grand maître" es sustituido por $\mathrm{H}$. de Balzac en "Le temps est un grand maigre" (Un debut dans la vie), Palimpsestes..., pp. 13-14. 
vale por "sobresalir o exceder en competencias o habilidades a otros, mereciendo el aplauso general"; ahora bien, "llevarse alguien la pala" puede valer, en este fragmento, por llevarse el instrumento (pala) utilizado en un metafórico homicidio.

La segunda intervención de Ariadna retoma una intervención de Fedra (la que antecede inmediatamente a los primeros versos del centón).

\section{ARIADNA: Teseo mío, dispón \\ De mi vida y mi persona, \\ Que a quien dice que te quiere, \\ Todo lo demás le sobra. \\ FEDRA: $\quad$ Esto supuesto, dispón \\ de mi vida y mi persona, \\ que a quien dice que te quiere, \\ todo lo demás le sobra.}

(Jornada tercera, escena IX, vv. 631-634)

Las dos intervenciones que siguen están tomadas de unos apartes de Lidoro, príncipe de Epiro, enamorado de Fedra, y de Baco, príncipe de Tebas, enamorado de Ariadna.

TESEO: Mucho temo que reviente El volcán en que me abraso.

ArIadna: Mucho temo que se asome Esta pasión a los labios.

LIDORO: (Mucho temo que reviente el volcán en que me abraso.)

BACO: (Mucho temo que se asome esta pasión a los labios.)

(Jornada primera, escena X, vv. 1259-1262)

La siguiente intervención de Teseo reproduce parte de un diálogo de éste con Ariadna. 
Teseo: $\quad$ Yo soy

El que soy porque soy vuestro,

Porque mi ser, de mi amor

Depende, y a no ser vuestro, pienso que no fuera yo.

ARIADNA: iQué turbados pasos da mi confusión!

¡Qué mucho, si va en mi culpa tropezando mi temor!

Pero acá se acerca un bulto, si no me engaña el horror de la noche; hablarle quiero. ¡Mas, ay, que la turbación me ha dejado el sobresalto, y se ha llevado la voz!

TESEO: (Aparte:

¡Vive Dios, que está esperando a la puerta! ¿Qué valor al suyo iguala?) - Señora.

ARIADna: ¿Quién es? ¡Ay de mí!

TESEO: Yo soy el que soy porque soy vuestro, porque mi ser, de mi amor depende, y a no ser vuestro, pienso que no fuera yo.

(Jornada tercera, escena XI, vv. 811-828)

Ariadna recita, a continuación, un verso de Lidoro.

ARIADNA: ¿Qué es lo que a mí me sucede?

LIDORO: ¿Qué es lo que a mí me sucede?

BACO: ¿Qué es lo que me ha sucedido?

(Jornada segunda, escena XIV, vv. 1059-1060)

El siguiente parlamento de Teseo conjunta intervenciones de Ariadna, Baco y Lidoro. El de Ariadna, una intervención al unísono de Fedra y Ariadna. 
Teseo: $\quad$ Determinado me alisto...

Para morir...

Para padecer...

Tu amante.

ARIADNA: ... siento que en mis confusiones, Amor es más laberinto.

ARIADNA: (Determinad $a$ me alisto...

BACO: $\quad$ (Yo a morir...

LIDORO: $\quad$ (Yo a padecer...

BACO: (Por amante.)

LIDORO: (Por rendido.)

FEDRA: (¿Pero, sabrá mi congoja...

ARIADNA: ([i]]Pero, sabrá mi delirio...

LAS DOS: (Sentir que en mis confusiones, Amor es más Laberinto? $)^{55}$

(Jornada segunda, escena XIV, vv. 1094-1100)

La última intervención de Teseo retoma unos versos dichos por Ariadna a Baco. ${ }^{56}$

TESEO: $\quad$ Noche oscura

Ampara mi amor, pues siempre

Empeños de amor ayudas.

ARIADNA: [...] ¡Noche oscura, ampara mi amor, pues siempre empeños de amor ayudas!

(Jornada tercera, escena X, vv. 782-784)

\footnotetext{
${ }^{55}$ En bastardilla en la edición consultada. En la editio princeps (1692), Fedra recita los dos últimos versos; en la de A. G. Salceda, los recitan Fedra y Ariadna. G. Schmidhuber cree que "la edición príncipe es la correcta, con el último parlamento de Fedra, que es a quien Teseo ama”, Sor Juana dramaturga, sus comedias “de falda y empeño", p. 179.

${ }^{56}$ Baco le ha dicho: "Señora, en el puerto hay surtas / naves (la que yo previne / servirá); la coyuntura / logremos, que prevenirla / no es menester, que antes muchas / quieren ya hacerse a la vela; / y si tú ahora aventuras / el poder salir, después / se puede ofrecer alguna / dificultad" (vv. 772-781).
} 
Escalante hace un cuidadoso montaje de los versos que ha elegido. Descontextualiza los versos de sor Juana y de fray de Guevara y, apropiándoselos, los recontextualiza en su centón. No está de más insistir, en este sentido, en que el contexto original no le impone ninguna restricción al momento de la recontextualización. Descompone y recompone. Y al disponer

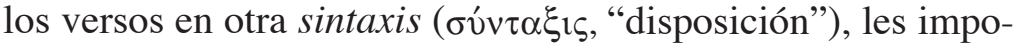
ne otro significado, un significado nuevo.

En la escena que sigue a la del centón, Fedra, que ha escuchado el diálogo entre Ariadna y Teseo, pregunta a su Nana:

FEDRA: ¿Por qué habla así mi hermana?

NANA: ¿Cómo?

FEDRA: Así, como todo al revés.

NANA: Se está enamorando.

FEDRA: Los enamorados usan otras palabras.

NANA: $\quad$ No son otras, son las mismas, suenan diferente.

FEDRA: Pobres, cómo deben confundirse. No se les entiende nada...

NANA: $\quad$ Ellos saben lo que dicen, saben lo que oyen.

(primera parte, escena VII)

Fedra, de diez años en esta primera parte, se extraña de la enrevesada manera de hablar de su hermana y de Teseo. Los enamorados, le explica la Nana, usan las mismas palabras que todos, pero en ellos "suenan diferente". La artificiosidad y el retorcimiento del lenguaje barroco de Amor es más laberinto pasan a ser, en esta explicación o interpretación de la Nana, la artificiosidad y el retorcimiento del lenguaje del amor. Ahora bien, así como los enamorados usan las mismas palabras que todos pero en ellos "suenan diferente", Ximena Escalante "usa" las palabras de sor Juana y fray de Guevara, que, descontextualizadas y recontextualizadas, significan otra cosa, significan diferente.

No hay que dejar de subrayar que, por un lado, en su centón Escalante hace un guiño al espectador (lector) atento al citar 
el verso que da título a la comedia, y que, por otro, en el breve diálogo que le sigue, da la pauta para interpretar dicho centón: lo mismo pero diferente.

Después de absorber y transformar múltiples textos, escribe Ximena Escalante Fedra y otras griegas, reescritura del tema de Fedra e Hipólito, tema que innova incorporando otras "historias", como la de Teseo y Ariadna. Para escribir la pieza, en la terminología de Genette, un hipotexto, un texto derivado, recurre la autora a muy variados procedimientos intertextuales, procedimientos que hablan de una consciente escritura "intelectual" y "erudita". Una vez más, no hay que buscar la originalidad en la materia, ofrecida por la tradición (más allá de la incorporación de otras "historias"), sino en su tratamiento, en su compleja y trabajada transformación poética.

\section{BIBLIOGRAFÍA}

\section{a) Fuentes}

Ausonius, with an English translation by Hugh G. Evelyn White, Cambridge, Harvard University Press / London: William Heinemann (Loeb Classical Library), 1961 (2 vols.).

D'Annunzio, Gabriele, Fedra, a cura di Pietro Gibellini, note di Tiziana Piras, Milano, Arnaldo Mondadori Editore (Collezione Oscar), 2001.

De La Cruz, Sor Juana Inés, Comedias, Sainetes y Prosa, edición, introducción y notas de Alberto G. Salceda, México, Fondo de Cultura Económica (Biblioteca Americana, 32; Obras completas de Sor Juana Inés de la Cruz, vol. 4), 1957.

-, Die Welt im Traum. Eine Dichtung der „Zehnten Muse von Mexiko“ Sor Juana Inés de la Cruz, Spanisch und Deutsch, Herausgegeben von Karl Vossler, Karlsruhe, Stahlberg Verlag, 1946.

-, Lírica personal, edición, introducción y notas de Alfonso Méndez Plancarte, México, Fondo de Cultura Económica (Biblioteca Americana, 18; Obras completas de Sor Juana Inés de la Cruz, vol. 1), 1951.

EsCalANTE, Ximena, Fedra y otras griegas, en AA. VV., El nuevo teatro II, introducción de Hugo Gutiérrez Vega, México, Ediciones El Milagro-Consejo Nacional para la Cultura y las Artes (Colección Nuestro Teatro), 1996, pp. 87-153. 
Escalante, Ximena, Fedra y otras griegas, México, Ediciones El Milagro-Consejo Nacional para la Cultura y las Artes (Colección La Centena), 2004.

EURIPIDES, Hippolytos, edited with introduction and commentary by W. S. Barrett, Oxford, Clarendon Press, 1992.

EurípIDes, Tragedias I. El Cíclope. Alcestis. Medea. Los Heraclidas. Hipólito. Andrómaca. Hécuba, introducción, traducción y notas de Alberto Medina González y Juan Antonio López Férez [la traducción del Hipólito es de A. Medina González], Madrid, Editorial Gredos (Biblioteca Clásica Gredos, 4), 1977.

-, Tragedias I [el volumen incluye las siguientes obras: El Cíclope, Alcestis, Medea, Los Heraclidas, Hipólito, Andrómaca y Hécuba], edición y traducción de Juan Antonio López Férez, Madrid, Ediciones Cátedra (Letras Universales, 36), 1985.

EurIPIDIs, Fabulae. Tomus I: Cyclops. Alcestis. Medea. Heraclidae. Hippolytus. Andromacha. Hecuba, edidit J[ames] Diggle. Oxonii, e Typographeo Clarendoniano (Scriptorum Classicorum Bibliotheca Oxoniensis / Oxford Classical Texts), 1984.

Hosidil Getae, Medea Cento Vergilianus, edidit Rosa Lamacchia, Leipzig, BSB B. G. Teubner Verlagsgesellschaft (Bibliotheca Scriptorum Graecorum et Romanorum Teubneriana), 1981.

KAnE, Sarah, Phaedra's Love, London, Methuen (Methuen Drama), 2002.

Mendoza, Héctor, Secretos de familia, iA la Beocia!, Reso, Fedra, introducción de Luis de Tavira, México, Ediciones El Milagro-Consejo Nacional para la Cultura y las Artes (Colección Teatro), 1996.

RaCine, Jean, Bajazet, Mithridate, Iphigénie, Phèdre, Esther, Athalie, Chronologie, préface et notices par André Stegmann, Paris, GF-Flammarion (Théâtre complet, vol. 2), 1996.

-, Phèdre, étude critique, texte intégral, avec un nouveau dossier pédagogique, Paris, Bordas (Univers des Lettres Bordas, 227), 1980.

SEnECA, Phaedra, edited by Michael Coffey and Roland Mayer, Cambridge, Cambridge University Press, 1990.

SÉnECA, Tragedias II. Fedra. Edipo. Agamenón. Tiestes. Hércules en el Eta. Octavia, introducción, traducción y notas de Jesús Luque Moreno, Madrid, Editorial Gredos (Biblioteca Clásica Gredos, 27), 1979.

SeneCAe, L. Annaei, Tragoediae. InCERTORUM AuCTORUM. Hercules [Oetaneus]. Octavia, recognovit brevique adnotatione critica instruxit Otto Zwierlein, Oxonii, e Typographeo Clarendoniano (Scriptorum Classicorum Bibliotheca Oxoniensis / Oxford Classical Texts), 1980.

SÉNÈQue, Tragédies. Tome I. Hercule furieux. Les Troyennes. Les Phéniciennes. Médée. Phèdre, texte établi et traduit par Léon Herrmann, 
édition revue, corrigée et augmentée d'un appendice bibliographique par J. Ph. Royer, Paris, Société d'Édition "Les Belles Lettres" (Collection des Universités de France), 1985 (6 $6^{\text {ème }}$ tirage).

Unamuno, Miguel de, Teatro, prólogo, edición y notas de Manuel García Blanco, Madrid, Afrodisio Aguado Editores-Libreros (Obras completas, tomo XII) (Paradilla del Alcor), 1962.

\section{b) Bibliografía especializada}

ANÓNIMO, "Fedra y otras griegas revienta historias", en Excelsior. El periódico de la vida nacional, México, 26 de mayo de 2002, p. 46.

BeníteZ, Roberto, "Ximena Escalante" [entrevista], en Universo [periódico de la Universidad Veracruzana], año 3, no. 129, Xalapa, Veracruz, 26 de enero de 2004. Internet: http://www.uv.mx/universo/129/arte/ arte04.htm.

BLOCK DE BEHAR, Lisa, Una retórica del silencio. Funciones del lector y procedimientos de la lectura literaria, Buenos Aires, Siglo XXI Editores (Lingüística y teoría literaria), 1994 (2a. ed. corregida).

BRunEl, Pierre, "Thématologie et littérature comparée", en Exemplaria. Revista internacional de Literatura Comparada, 1, 1997, pp. 3-12.

Chantraine, Pierre, Dictionnaire étymologique de la langue grecque. Histoire des mots, avec un Supplément sous la direction de Alain Blanc, Charles de Lamberterie, Jean-Louis Perpillou, Paris, Librairie C. Klincksieck et Cie., 1999.

DANE II, Nathan, "The Medea of Hosidius Geta", en The Classical Journal, 46, 2, November, 1950, pp. 75-78.

Ernout, A., et A. Meillet, Dictionnaire étymologique de la langue latine. Histoire des mots, Paris, Librairie Klincksieck, $1967^{4}$.

FRISK, Hjalmar, Griechisches etymologisches Wörterbuch, Heidelberg, Carl Winter Universitätsverlag, 1973, 1970, 1972 (3 vols.).

Genette, Gérard, Palimpsestes. La littérature au second degré, Paris, Éditions du Seuil (Poétique), 1982.

Jakobson, Roman, "Linguistics and Poetics", en Thomas A. Sebeok (ed.), Style in Language, Cambridge, The Technology Press of Massachusetts Institute of Technology / New York-London, John Wiley \& Sons, 1960, pp. 350-377.

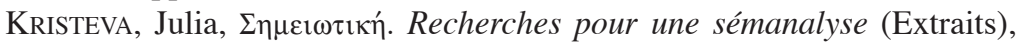
Paris, Éditions du Seuil (Points Littérature), 1969.

Paz, Octavio, Sor Juana Inés de la Cruz o las trampas de la fe, edición del autor, México, Fondo de Cultura Económica (Letras mexicanas, Obras completas de Octavio Paz, vol. 5), 1994. 
SCHMIDHUBER DE LA MorA, Guillermo, Sor Juana dramaturga, sus comedias "de falda y empeño", Puebla, Consejo Nacional para la Cultura y las Artes-Benemérita Universidad Autónoma de Puebla, 1996.

Trousson, Raymond, "Les Études de thèmes. Questions de méthode", en R. Trousson und Adam John Bisanz (Hgg.) in Verbindung mit Herbert A. Frenzel, Elemente der Literatur: Beiträge zur Stoff-, Motiv- und Themenforschung. Elisabeth Frenzel zum 65. Geburstag, Stuttgart, Alfred Kröner Verlag (Kröner Themata), 1980 (2 vols.), vol. 1, pp. $1-10$.

Vossler, Karl, Die “zehnte Muse von Mexico” Sor Juana Inés de la Cruz, München, Verlag der Bayerischen Akademie der Wissenschaften in Kommission bei der C. H. Beck'schen Verlagsbuchhandlung, 1934 (Sitzungsberichte der Bayerischen Akademie der Wissenschaften [zu München], Philosophisch-historische Abteilung, Jahrgang, 1934, Heft 1)

WALDE, Alois, Lateinisches etymologisches Wörterbuch. 3, neuebearbeitete Auflage von Johann Baptist Hoffmann. Heidelberg, Carl Winter's Universitätbuchhandlung / Carl Winter Universitätsverlag (Indogermanische Bibliothek, Wörterbücher), 1938, 1954 y 1938 (3 vols.). 